Proceedings of the 2011 Winter Simulation Conference

S. Jain, R.R. Creasey, J. Himmelspach, K.P. White, and M. Fu, eds.

\title{
INTEGRATING REALTIME PROJECT PROGRESS INPUT INTO A CONSTRUCTION SIMULATION MODEL
}

\author{
Hua Xie \\ Simaan AbouRizk \\ Dept. of Civil \& Environmental Engineering \\ University of Alberta \\ Edmonton, AB T6G 2W2, CANADA
}

\author{
Siri Fernando \\ Design and Construction Drainage Services \\ City of Edmonton \\ Edmonton, AB T5M 3B8, CANADA
}

\begin{abstract}
Computer simulation has been widely applied in modeling construction operation to gain insight into project performance. However, simulation models are rarely used after the project planning and design stage. One main constraint is the time and effort needed for collecting pertinent and correct information and processing it for input into the model. As projects progress and project circumstances change, simulation model inputs need to be updated to reflect these changes and maintain model validity. This paper demonstrates the integration of real time progress data into a simulation model, using a tunnel construction project as an example. A progress monitoring system was developed to capture progress data, and provide real time project progress input into a simulation model. The simulation model is able to revise the inputs in light of the actual progress and provide long-term support through project execution.
\end{abstract}

\section{INTRODUCTION}

Computer simulation has been widely applied in modeling construction operation to gain insight into project performance. It helps improve project performance, which can result in reduced project cost, improved project quality, and shortened duration (Abourizk 2010). Simulation models are able to provide the long-term performance analysis for planning and design, but they are rarely used after the project planning and design stage (Moon and Phatak 2005). One main constraint is the time and effort needed in gathering and extracting pertinent information for simulation models (Bengtsson et al. 2009; Moon and Phatak 2005; Skoogh, Michaloski, and Bengtsson 2010). This, to some extent, constrains traditional simulation models from repetitive and long-term usage (Moon and Phatak 2005). The lack of tools and methods for timely communication and interaction between model developers and field engineers is also a limiting factor for simulation models to provide long-term continuous support through project execution.

Maintaining valid model inputs is a challenge for long-term usage of simulation models. When developing a discrete simulation model for a project which has not started, model inputs are usually assumed. The assumptions are based upon historical data from similar projects and similar activities and from experts' judgments. As projects progress and project circumstance changes, simulation model inputs need to be updated to reflect these changes, so as to maintain model validity.

This research presents a progress monitoring system which was developed to capture progress data, and provide real time project progress input into a simulation model. The progress monitoring system is a database application for collecting progress data from a tunnel construction site. It feeds these progress data into a tunnel simulation model. The system provides a convenient way to capture site data in real time. This provides a chance to quickly update simulation model inputs, by extracting pertinent information according to real time data. Then the simulation model is able to provide long-term support through overall project execution. In addition to supporting the simulation model, the monitoring system can be 


\section{Xie, AbouRizk and Fernando}

used alone for progress analysis. This is discussed in detail in this paper as well. In all, this paper demonstrates integrating real time progress data into a simulation model, and presented a case study for a tunnel construction project.

\section{LITERATURE REVIEW}

\subsection{Model input management}

Effective input management for simulation models has been recognized to be important in repetitive usage of models (Bengtsson et al. 2009; Moon and Phatak 2005; Skoogh, Michaloski, and Bengtsson 2010). The Input data management process covers from the raw data collection from different sources to data process and entering inputs into the DES model (Boulonne et al. 2010). Skoogh, Michaloski, and Bengtsson (2010) stated that DES is usually applied for special purpose studies, instead of helping daily business for production engineers, despite its power as a tool for efficiency improvements in production.

A few examples of model input management and timely updating are found in literature review from manufacturing industry in the last few years. Bengtsson et al. (2009) proposed a methodology for Input Data Management (IDM) in Discrete Event Simulation projects, which covers the process of identifying and collecting data, and using an IDM software to extract and process the data. Boulonne et al. (2010) proposed a simulation data architecture to facilitate data sharing between data sources and DES models. They developed a data processing tool, a database and an interface to provide reusable resource event data for sustainable resource information in DES models. Skoogh, Michaloski, and Bengtsson (2010) presented an approach for automated raw data collection and processing for simulation information, in order to improve the reuse of DES models by reducing the time-consumption for input data management.

Unlike the manufacturing industry, the construction profession usually has to deal with scattered construction sites and labor-intensive projects. Every project has its own properties and uncertainty. It is difficult to find a standard way of collecting project progress. Human judgments are always required in determining overall project progress. Database applications for project monitoring and control are commonly used by construction companies. Automated construction data collection is still on the stage of seeking good applications. This study focuses on integrating progress data into a simulation model, and automated data collection is not a part of the study.

\subsection{Discrete event simulation in construction}

Discrete event simulation (DES) has been successfully applied into modeling construction operations (Abourizk 2010) since the first construction simulation tool, CYCLONE, introduced by Halpin (1977). Many other simulation tools were later developed to model various construction operations, such as STROBOSCOPE (Martinez and Ioannou 1994), Simphony (AbouRizk and Hajjar 1998), and so on.

A literature review shows several simulation models in tunnel construction that have been developed using these construction DES tools. As tunnel construction operations are normally linear and repetitive, they are especially suitable for DES. Touran (1987) applied CYCLONE to predict the advance rate of a small diameter tunnel in soft rock. Ruwanpura (2001) developed a special purpose simulation (SPS) template for tunnel construction operations, which proposed and implemented a new analytical model to predict the soil types and soil families along the tunnel path. Integrated simulation methods were then implemented in the SPS template to determine tunnel productivity. Chung, Mohamed, and Abourizk (2006) applied Bayesian updating methods into a tunnel simulation model and then developed and implemented a simulation-based productivity model for utility tunnel construction operations in order to identify the effects of uncertain factors, improve the prediction of tunnel boring machine penetration rates, and predict productivity under various project circumstances and soil conditions. A general purpose simulation was developed using Simphony for modeling space, logistics and resource dynamics with genetic algorithms for optimizing the layout based on various constraints and rules (Zhou, AbouRizk, and Al-Battaineh 


\section{Xie, AbouRizk and Fernando}

2009; Zhou, AbouRizk, and Fernando 2008). These simulation models in tunnel construction application have been mainly employed to improve prediction of the productivity or advancement rate in real world.

Tunnel simulation models also help engineers make better decisions in project planning. Al-Bataineh (2008) employed the idea of a scenario-based project planning tool, following an approach recommended by FIATECH for construction project planning, and incorporated various project information, including cost, schedule, productivity, weather effects, material supply, and dirt handling. He developed a method of establishing communication between different simulation templates or simulation elements, deploying these within a simulation-based tool for tunnel construction implemented in Simphony.NET. In addition, Al-Bataineh (2008) proposed a multi-user framework of tunnel construction simulation.

However, most of these simulation models have tried to improve project performance before actual site construction commences. Long-term decision-making support from simulation models is seldom discussed in literature review.

As pointed out by Moon and Phatak (2005), simulation models are usually applied before the initial plans or designs of a project are finalized, and these models are not designed for repetitive usage, because gathering and extracting pertinent information for simulation models is time-consuming and laborious (Bengtsson et al. 2009; Boulonne et al. 2010; Moon and Phatak 2005). Still, the data collection process is the most crucial stage through model development (Robertson and Perera 2002). Boulonne et al. (2010) stated that on average $31 \%$ of total project time is used in input data management for projects using DES to analyze and improve material flows in production. Therefore, improved input data collection and analysis can reduce model development cycle, and allow simulation models provide long-term reliable support. The progress monitoring system in this research is developed for this purpose. It provides real time project progress input into a simulation model.

\subsection{HLA-based simulation}

Another challenge in construction operation simulation is to feed distributed information to a local simulation model. All these well-known construction simulation tools only allow a simulator to develop models in a local computer, and mean that a model developer must collect and set up all model inputs and run the simulation model in a specific environment. When input data are scattered across different sources and locations, data collection become laborious.

The COSYE platform (Construction Synthetic Environment) was proposed by AbouRizk (2006) to address this issue. The COSYE simulation environment is a .NET implementation of the HLA (High Level Architecture) standard (Kuhl, Dahmann, and Weatherly 2000). It provides an environment to develop a variety of DES models for construction operations.

The High Level Architecture (HLA) serves as a standard framework designed to construct simulations composed of different individual simulation components. HLA was first developed by the Defense Modeling and Simulation Office (DMSO) of the United States Department of Defense (DoD) to meet the needs of defense-related projects (Defense and Simulation 1996).

HLA was adopted as an open standard (IEEE Standard 1516) in 2000 by the Institute of Electrical and Electronic Engineers (IEEE), and is now increasingly being applied in simulation fields such as training, traffic control, construction plan and control, extending its original application in military field defense. It provides an efficient and cost-effective tool for analyzing the targeted system in various ways. HLA is widely used for training, entertainment, virtual shopping malls, and testing or evaluating hardware (Li 2003; Lu 2006; Park 2005).

A simulation system based on the design principles of HLA is referred to as a federation. Federates are the simulation components of the federation. They can be simulators, interfaces to a human user, or databases that store information for other federates. In this research, the tunnel construction simulation system is referred as a tunnel federation. 


\section{TUNNEL CONSTRUCTION PROCESS}

A tunnel project starts with the selection of the site location. During this stage, a project team takes into account a number of factors, including availability of water supplies, electricity, easy access points, and space to store material on site. Then, a construction crew will excavate a working shaft, a tail tunnel, and the undercut in sequence. After all these are done, the construction crew can start digging the tunnel.

A tunnel can be excavated by TBM, or by a crew using tools like a jackhammer, which is called hand tunnelling. While digging a tunnel, one train consisting of a few muck carts is employed to remove dirt from the tunnel face to the bottom of the working shaft. Then, a crane is used to lift muck carts one at a time and dump dirt above ground. Sometimes, the construction crew will install a switch to accommodate two trains in a tunnel, so as to accelerate the tunnelling operation; this process will be referred to here as "full-capacity tunnelling." One train travels to the TBM and unloads the material car, which usually represents concrete liners or rib and lagging. Then, the TBM starts to excavate. When the train is full, it starts traveling toward the working shaft at the same time as the TBM starts installing the material to support the tunnel. Once the full train reaches the working shaft, the other train (if empty) starts travelling towards the TBM. When that train reaches the TBM, it begins excavating the next section, if TBM has completed material installation. If not, the train waits. When the train reaches the working shaft, the crew checks whether the previous train has finished unloading. If yes, the train can start unloading the dirt and loading material; if no, the second train should wait until the previous train finishes.

This operation repeats until the TBM reaches the end of the tunnel. During that time, a removal shaft is constructed in the same way as the working shaft. A removal shaft is used to remove TBM from tunnel at the end of a project. The construction process described above is modeled in the tunnel federation.

\section{SYSTEM ARCHITECHTURE AND DESIGN}

\subsection{Conceptual design}

This study proposed a progress monitoring system to provide real-time input for tunnel federation. The information flow process is described in Figure 1, as shown below. The progress monitoring system is used for collecting and analyzing project information. Site engineers can enter data into the progress monitoring system through a personal digital assistant (PDA) or a computer. These data are saved in a database server. The tunnel simulation system can then retrieve these data and process them to update model inputs. 


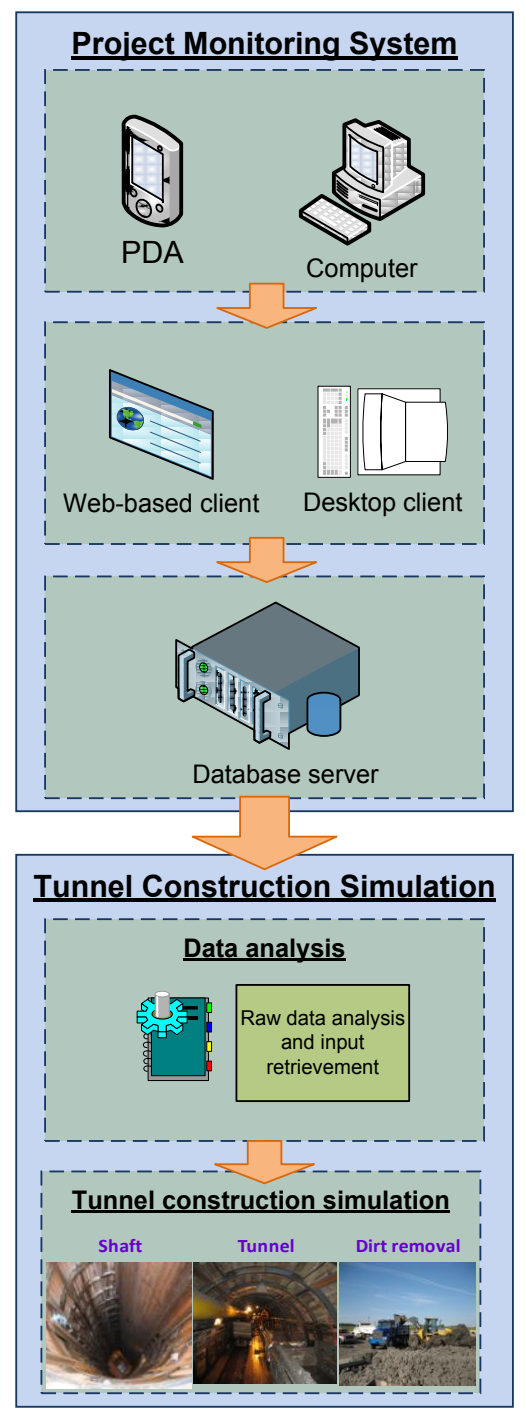

Figure 1. Conceptual design of distributed tunnel construction monitoring and simulation

\subsection{Progress monitoring}

The progress monitoring system is designed to collect and analyze project progress data, and to provide the basis of simulation model inputs. The progress monitoring system is built using the DADE framework, a database application development platform which is written in Delphi. It provides two types of database solutions. A web-based solution is developed for users to enter data through a browser. It can be used with both PDAs and computers. A desktop solution also provides data analysis and reporting function to help users understand the ongoing projects.

\subsection{Tunnel construction simulation}

The tunnel simulation model is developed using the COSYE platform (Abourizk 2006). It is called the tunnel federation, as it follows HLA standards. This tunnel federation simulates the overall construction process of a utility tunnel. In this study, the process covers the construction of a working shaft, the main utility tunnel, a removal shaft, some access shaft, an undercut if need. The main components of the tunnel federation are introduced here, as shown in Figure 2. 


\section{Xie, AbouRizk and Fernando}

This research divided the federation into four groups of federates: input analysis, construction process simulation, visualization, and the support federate group. Input analysis processes raw data that was collected from the job site and stored in a database. It provides inputs for construction process federates, which simulate the actual construction process. Visualization federates display the simulation process in different formats. The details of the visualization federates were presented by Yang et al. (2010). The support federates try to represent and model aspects of the construction environment that could affect tunnel construction production. For example, the procurement of liners for tunneling is modeled by the procurement federate, and the dispatching and supplying of liners to a specific jobsite is modeled in the supplier federate. The calendar federate also models workdays, holidays, shift configuration and so on. The scenario setup allow user to configure different construction scenarios, such as number of shafts or tunnel length. The breakdown federate models machine breakdowns.

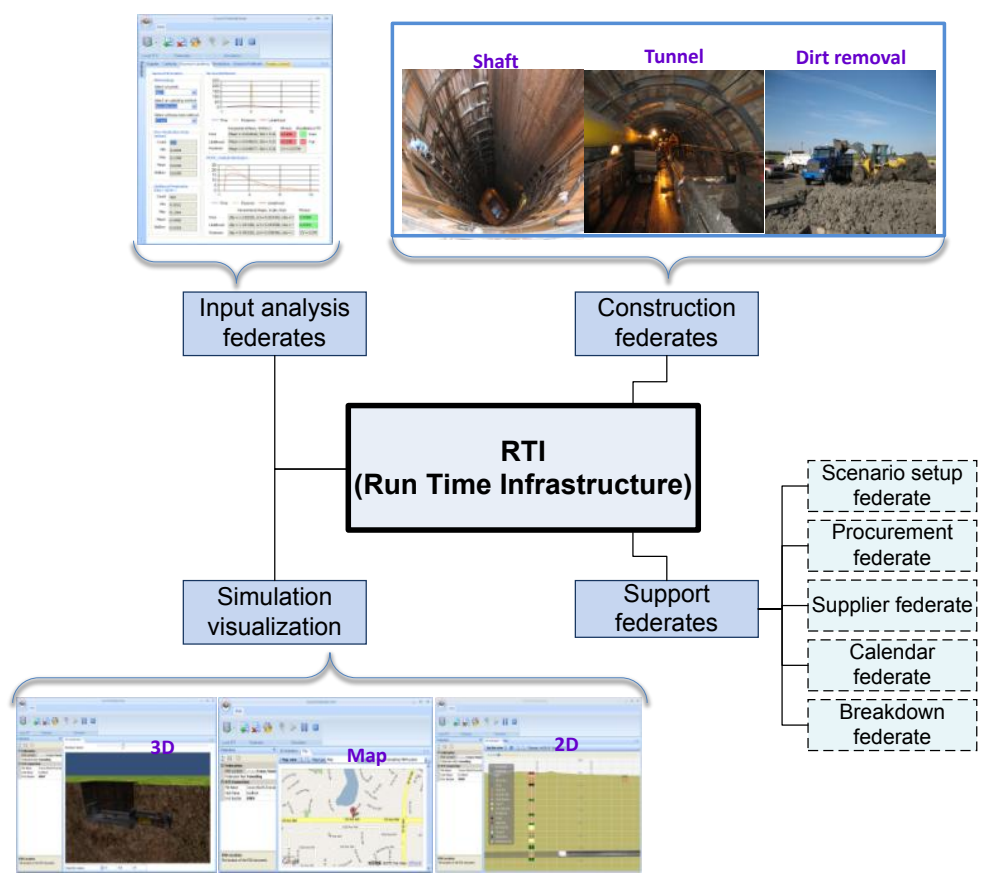

Figure 2. Tunnel simulation model

\section{CASE STUDY}

\subsection{Project introduction}

This research is based on the practice of tunnel construction in the City of Edmonton, Alberta by the Design and Construction Section of Drainage Services of the City's own workforce (D\&C). This case study project is called the North Edmonton Sanitary Trunk (NEST) NL 2,3, and is located in Edmonton, AB, Canada. NEST was selected to represent a typical utility tunnel project; it is 3707 meters in length, and 2.344 meters in diameter. The project started in Dec 2007 using a tunnel boring machine (TBM). The tunnelling operations have been monitored and data about the production progress have been recorded since construction began, as well as all interruptions.

\subsection{Process of progress monitoring}

The process monitoring and information is discussed in this section. The information transfer flow in D\&C without using a progress monitoring system is shown in Figure 3a. It takes an unacceptably long 


\section{Xie, AbouRizk and Fernando}

time to transfer site information to a project manager who is working in the head office. In this situation, project managers have limited access to detailed project schedules. It is difficult to track the progression of contract commitments as they occur on a project, which leads to delayed response to cost and scheduling problems and a reactive project management environment. The proposed information flow using the monitoring system is described in Figure $3 \mathrm{~b}$. The site engineers can record construction information and send them to a database. As a result, the simulation model is able to retrieve progress data in real time. In addition, the project managers and analysts are able to access project progress in real time.

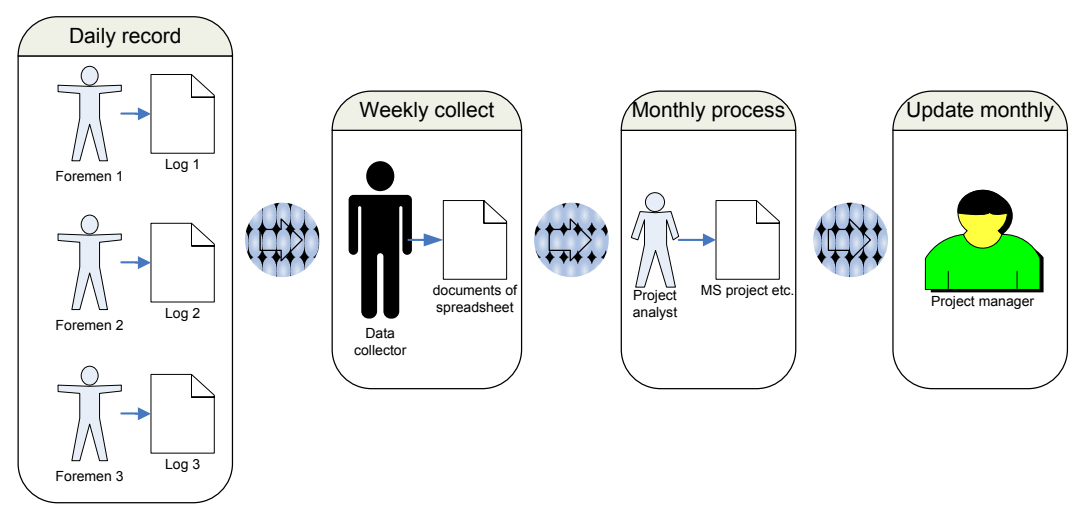

a) The process of traditional information flow

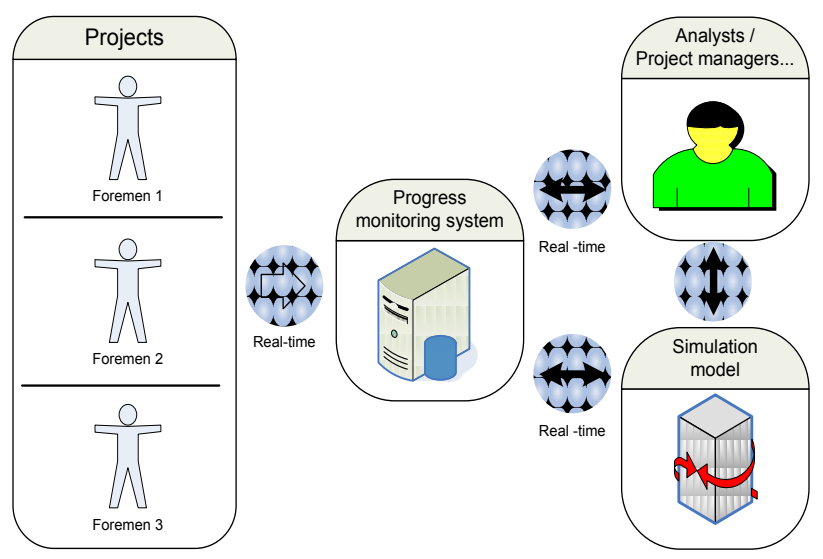

b) The process of proposed information flow

Figure 3: Process of data flow

\subsection{Data collection}

Both the web-client and the desktop client support progress monitoring and data entry in real time. The web-based client allows users to entry project information through all kinds of personal digital assistants (PDAs) such as the Blackberry ${ }^{\mathrm{TM}}$ or $\mathrm{iPhone}^{\mathrm{TM}}$, as long as the Internet is available. This client provides the flexibility to enter data whenever new information is available and captured. It is useful when construction job sites are scattered and information is distributed. The web client focuses on functions of data entry and review. The data entry interfaces of web client is shown in Figure 4. Progress data of a tunnel project can be entered here, including shift duration, shift number, number of foremen, number of operator, number of laborer, production, TBM working hours, and so on. The web client focuses on convenient and practical daily usage; it allows inspectors, foremen, and site engineers to simply capture data in a convenient way. 


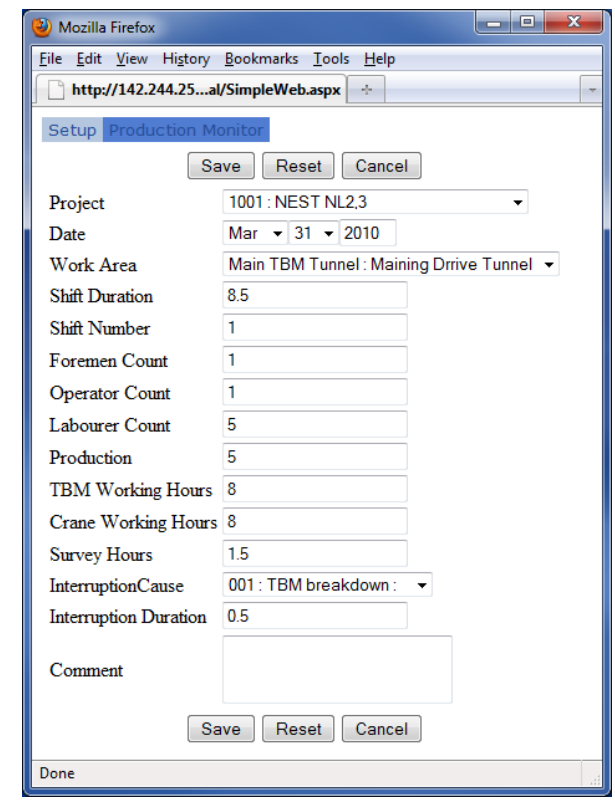

Figure 4. The web-based client for progress monitoring

The desktop client provides more functions of data analysis and reporting. The interface for data entry is shown in Figure 5. It collects same information as in the web client, but gives a better view of all project information, and allows searching and filtering for data analysis. It should fit project managers' requirement in reviewing and analyzing data, and help them to better understand the project progress.

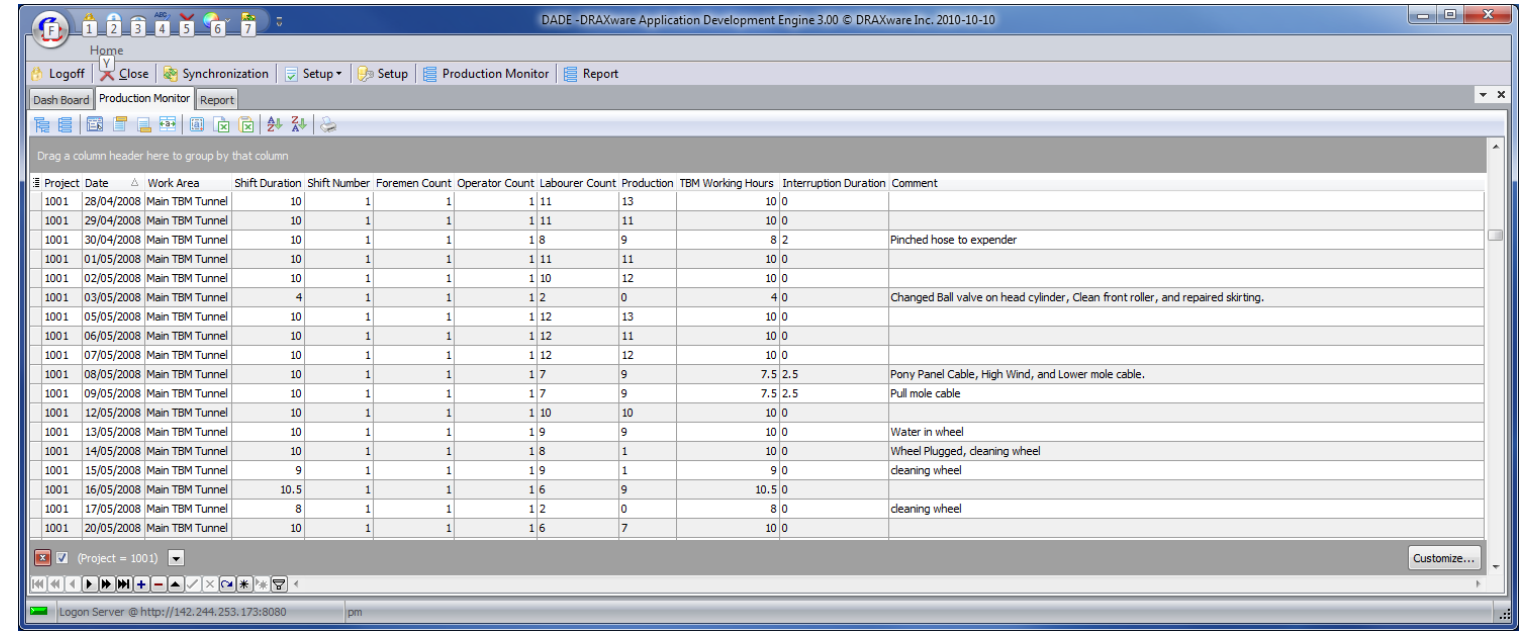

Figure 5. The desktop client for progress monitoring

\subsection{Data analysis and reporting}

The desktop client provides rich data analysis and report generation in addition to data entry and review as in the web solution. Three types of reports are provided, based on daily production, weekly production, and monthly production. Sample reports are presented in Figure 6. The monthly report summarizes the progress of every month for each project. It show the remaining length of a project, the average production per shift, and the estimated shifts to completion based on the productivity of the current month. In addition, average crew size, average shift length of each month, and total interruption duration of a month 
are included in the report as well. Similar to the monthly report, the weekly report and daily report are based on weekly project progress and daily progress, respectively.

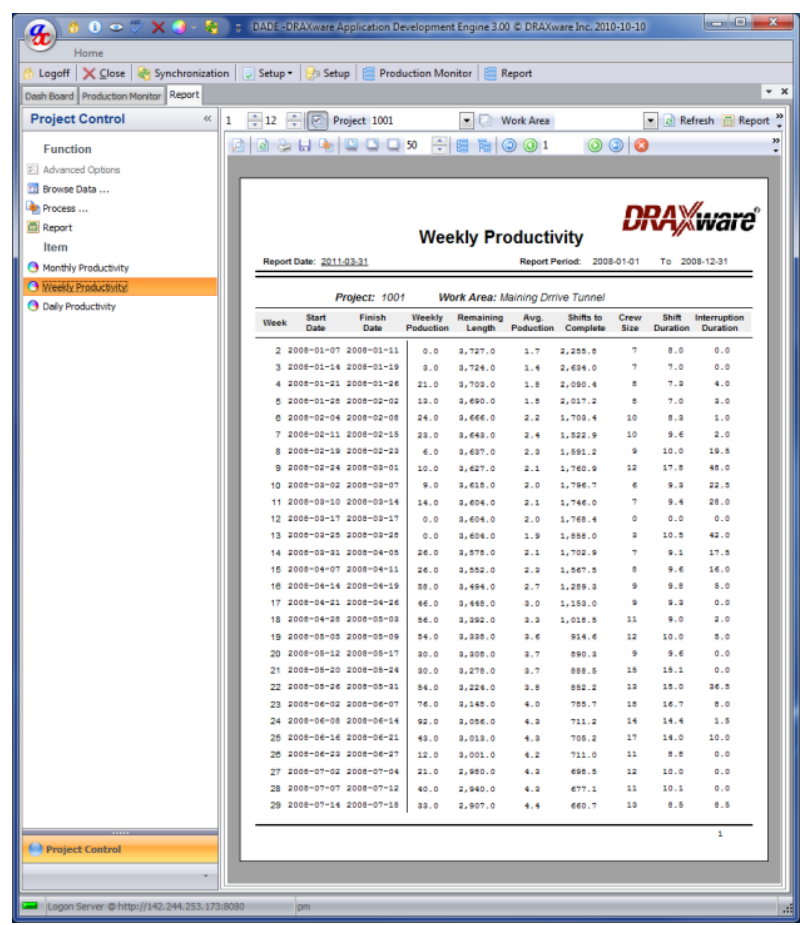

Figure 6. Weekly progress report in progress monitoring system

Graphical analysis is also provided in the progress monitoring system. It provides a better understanding of production changes and production trends. Figure 7a shows the monthly production from 2008 to 2009 in a bar graph format. An average production line is added for trend analysis. Figure $7 \mathrm{~b}$ shows the production of 2009 in a pie chart.

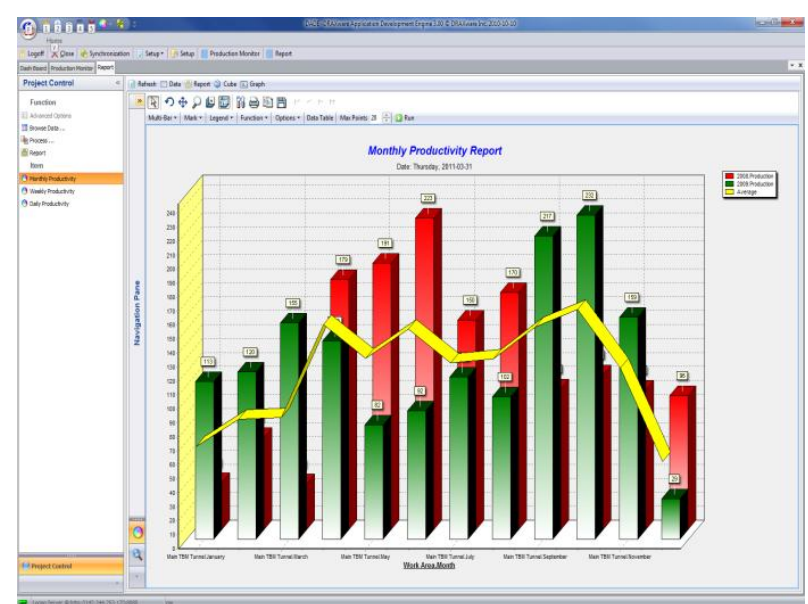

a) Monthly production bar graph

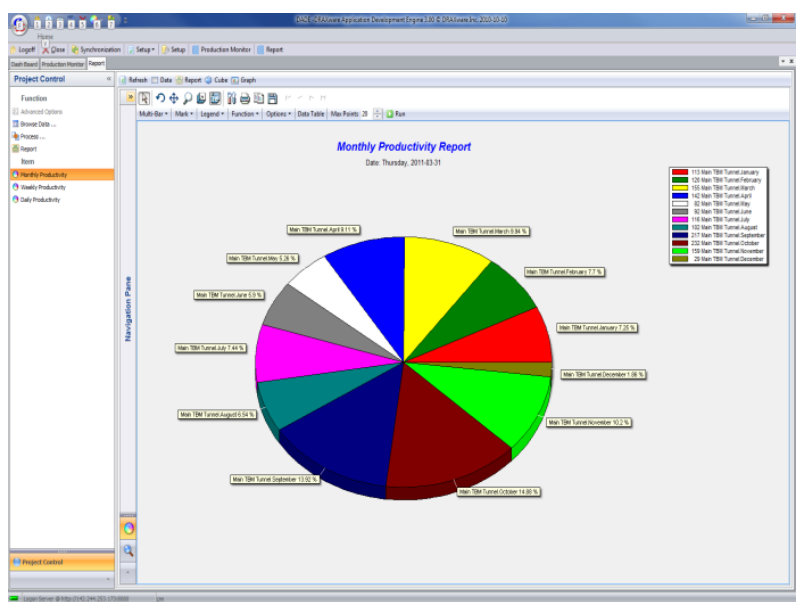

b) Monthly production pie chart

Figure 7. Examples of graphic analysis in progress monitoring 


\section{Xie, AbouRizk and Fernando}

\subsection{Model input analysis}

Simulation model inputs are based on historical data and site observations. This study uses the penetration rate of the TBM as an example to illustrate how progress data is utilized and model input is calculated in simulation. TBM is the key resource in TBM tunneling. Its production efficiency is defined by penetration rate, representing the excavating distance per unit time. Ourdev, Abourizk, and Al-Bataineh (2007) proposed a way of inferring TBM penetration rate based on tunnel progress data. This study followed their method, and is reviewed here briefly.

TBM penetration rate is calculated as the daily production divided by the TBM's corresponding production time. The production time equals the total time needed to complete 1 meter tunnel minuses supporting time. The supporting time includes the time of crew mobilization, break, dirt removal, lining, resetting, material loading, dirt dumping. More details can be found in Ourdev, Abourizk, and Al-Bataineh (2007).

\subsection{Use of data in simulation model}

After all data is processed, the list of penetration rates is the basis of model inputs. The histogram of the data set is first analyzed, and then the data is fitted to statistical distributions. The best fit distribution will be selected and used as input for the simulation model. One penetration rate data point can be obtained from the progress of a shift. Figure 8a shows the analysis of 150 data points. Four distributions are fitted to the data. The Beta distribution and Gamma distribution are almost overlapped; they show a better match to the histogram and are recommended in this study to use as model input. An exponential distribution fitting is also good, but the normal distribution should not be used.

Model inputs should be continuously updated as more data becomes available. Figure $8 \mathrm{~b}$ shows the input analysis of all 366 data points in this case project. Beta and Gamma distributions still fit the histogram better than other two distribution. Table 1 shows a basic statistical analysis of 150 data points and 366 data points and the results of fitting to Beta and Gamma distributions. The mean penetration rate increased from 0.035 meter per minute to 0.042 meter per minute, which means the TBM production increased 20\% from the first 150 data points gathered. The parameters of fitted distribution also changed substantially. However, the standard error of estimated parameters converged as data points increased. For example, in Beta distribution fitting, the $a$ parameter changed from 1.051 to 1.312 , but the estimation error reduced from 0.139 to 0.100 . This demonstrates the value of updating model inputs to maintain valid model inputs, which allows the simulation model to provide reliable long-term support.

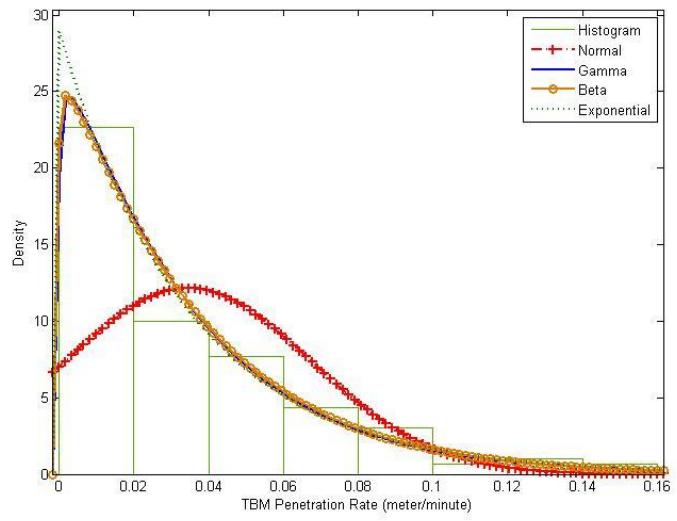

a) Input analysis of 150 data points

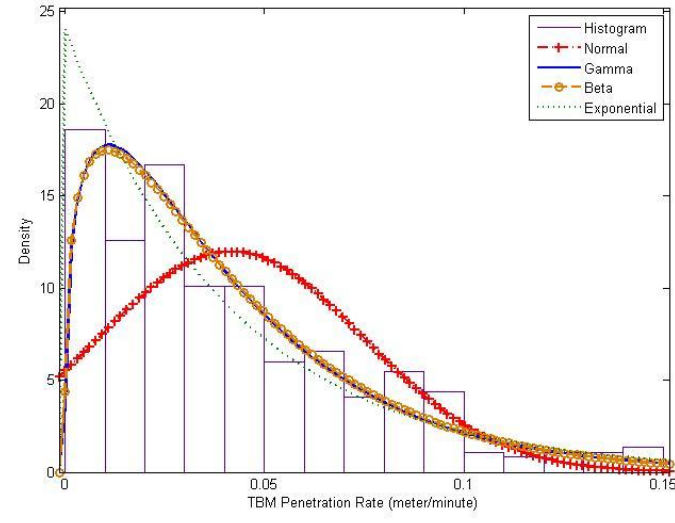

b) Input analysis of 366 data points

Figure 8. Simulation model input analysis 


\section{Xie, AbouRizk and Fernando}

Table 1. Statistical analysis of TBM penetration rate

\begin{tabular}{|c|c|r|r|r|r|r|r|}
\hline $\begin{array}{c}\text { Distribution } \\
\text { type }\end{array}$ & $\begin{array}{c}\text { Data } \\
\text { points }\end{array}$ & Mean & Variance & Parameter $a$ & $\begin{array}{c}\text { Std. Error } \\
\text { of } a\end{array}$ & Parameter $b$ & $\begin{array}{c}\text { Std. Error } \\
\text { of } b\end{array}$ \\
\hline \multirow{2}{*}{ Gamma } & 150 & 0.035 & 0.001 & 1.080 & 0.111 & 0.032 & 0.004 \\
\cline { 2 - 8 } & 366 & 0.042 & 0.001 & 1.354 & 0.090 & 0.031 & 0.002 \\
\hline \multirow{2}{*}{ Beta } & 150 & 0.035 & 0.001 & 1.051 & 0.139 & 29.360 & 4.559 \\
\cline { 2 - 8 } & 366 & 0.042 & 0.001 & 1.312 & 0.100 & 30.298 & 2.920 \\
\hline
\end{tabular}

\section{CONCLUSION}

The main purpose of the study is to demonstrate the integration of real time progress input into a distributed tunnel construction simulation model. This paper presented a progress monitoring system for monitoring and analyzing tunnel progress. Information from scattered construction sites is captured and recorded in the database in real time through the system. The web client allows a user to capture data using PDAs such as the iPhone ${ }^{\mathrm{TM}}$. The reporting and analysis function from the desktop client is also presented in this paper. The progress monitoring system works in conjunction with an HLA-based tunnel construction simulation, contributing to a tunnel simulation model with real time progress input. With real time data capture and process, the tunnel simulation model is able to provide long-term reliable decision support. A case study of tunnel construction simulation is presented to illustrate how the data monitoring system can ease the time and effort needed in capturing scattered data and retrieving model inputs.

\section{REFERENCE}

Abourizk, S. 2006. "Collaborative Simulation Framework for Multi-user Decision Support in Construction" (Vol. 85321972).

Abourizk, S. 2010. "Role of simulation in construction engineering and management". Journal of Construction Engineering and Management, 136(10), 1140-1153.

AbouRizk, S. M., and D. Hajjar. 1998. "A framework for applying simulation in construction". Canadian Journal of Civil Engineering, 25(3), 604-617.

Al-Bataineh, M. 2008. "Scenario-based planning for tunnelling construction" Ph.D. thesis, University of Alberta (Canada), Canada

Bengtsson, N., G. Shao, B. Johansson, Y. T. Lee, S. Leong, A. Skoogh, and C. McLean. 2009. "Input Data Management Methodology for Discrete Event Simulation." In Proceedings of the 2009 Winter Simulation Conference, edited by M. D. Rossetti, R. R. Hill, B. Johansson, A. Dunkin and R. G. Ingalls, 1335-1344. Piscataway, New Jersey: Institute of Electrical and Electronics Engineers, Inc.

Boulonne, A., B. Johansson, A. Skoogh, and M. Aufenanger. 2010. "Simulation data architecture for sustainable development." In Proceedings of the 2010 Winter Simulation Conference, edited by B. Johansson, S. Jain, J. Montoya-Torres, J. Hugan, and E. Yücesan. 3435-3446. Piscataway, New Jersey: Institute of Electrical and Electronics Engineers, Inc.

Chung, T. H., Y. Mohamed, and S. Abourizk. 2006. "Bayesian updating application into simulation in the North Edmonton Sanitary Trunk tunnel project". Journal of Construction Engineering and Management, 132(8), 882-894.

Defense, M., and O. Simulation. (1996). HLA Time Management Design Document Retrieved March 30, 2011, 2010, from http://www.cc.gatech.edu/computing/pads/PAPERS/HLA-TM-1.0.pdf

Halpin, D. W. 1977. "CYCLONE - method for modeling job site processes". American Society of Civil Engineers, Journal of the Construction Division, 103(3), 489-499.

Kuhl, F., J. Dahmann, and R. Weatherly. 2000. Creating computer simulation systems : an introduction to the high level architecture. Upper Saddle River, NJ: Prentice Hall PTR.

Li, L. 2003. "DSP hardware surrogate for the HLA" M.A.Sc. thesis, Carleton University, Canada 


\section{Xie, AbouRizk and Fernando}

Lu, K. 2006. "Data distribution management schemes for HLA-compliant distributed simulation systems" M.C.S. thesis, University of Ottawa, Edmonton, Alberta, Canada

Martinez, J. C., and P. G. Ioannou. 1994. "General purpose simulation with Stroboscope." In Proceedings of the 1994 Winter Simulation Conference, edited by J.D. Tew, S. Manivannan, D. A. Sadowski, and A. F. Seila, 1159-1166. Piscataway, New Jersey: Institute of Electrical and Electronics Engineers.

Moon, Y. B., and D. Phatak. 2005. "Enhancing ERP system's functionality with discrete event simulation". Industrial Management and Data Systems, 105(9), 1206-1224.

Ourdev, I., S. Abourizk, and M. Al-Bataineh. 2007. "Simulation and uncertainty modeling of project schedules estimates." In Proceedings of the 2007 Winter Simulation Conference, edited by S. G. Henderson, B. Biller, M.-H Hsieh, J. Shortle, J. D. Tew, and R. R. Barton, 2128-2133. Piscataway, New Jersey: Institute of Electrical and Electronics Engineers, Inc.

Park, J. 2005. "A framework to model complex systems via distributed simulation: A case study of the virtual test bed simulation system using the high level architecture" Ph.D. thesis, University of Central Florida, Florida, United States

Robertson, N., and T. Perera. 2002. "Automated data collection for simulation?". Simulation Practice and Theory, 9(Copyright 2002, IEE), 349-364.

Ruwanpura Arachchige, J. Y. 2001. "Special purpose simulation for tunnel construction operations" Ph.D. thesis, University of Alberta, Edmonton, Alberta, Canada

Skoogh, A., J. Michaloski, and N. Bengtsson. 2010. "Towards continuously updated simulation models: combining automated raw data collection and automated data processing." In Proceedings of the 2010 Winter Simulation Conference, edited by B. Johansson, S. Jain, J. Montoya-Torres, J. Hugan, and E. Yücesan, 1678-1689. Piscataway, New Jersey: Institute of Electrical and Electronics Engineers, Inc.

Touran, A., and A. Toshiyuki. 1987. "Simulation of tunneling operations". Journal of Construction Engineering and Management, 113(4), 554-568.

Yang, Z., E. Moghani, S. M. AbouRizk, and S. Fernando. 2010. "3D CAD modeling and visualization of the tunnel construction process in a distributed simulation environment." In Proceedings of the 2010 Winter Simulation Conference, edited by B. Johansson, S. Jain, J. Montoya-Torres, J. Hugan, and E. Yücesan, 3189-3200. Piscataway, New Jersey: Institute of Electrical and Electronics Engineers, Inc.

Zhou, F., S. M. AbouRizk, and H. Al-Battaineh. 2009. "Optimisation of construction site layout using a hybrid simulation-based system". Simulation Modelling Practice and Theory, 17(2), 348-363.

Zhou, F., S. M. AbouRizk, and S. Fernando. 2008. "A simulation template for modeling tunnel shaft construction". In, 2455-2461. Miami, FL, United states. 